\title{
A Review on Copper Recovery from Waste PCBs
}

\author{
A.M. JI \\ Hebei Key Laboratory of Modern Metallurgy Technology, Tangshan, China
}

H.Y. LIU, Z.H. HU

Environmental protection bureau of Tangshan, Tangshan, China

\begin{abstract}
Copper content is higher than other metal in the waste printed circuit boards (PCBs), therefore, recycling of copper from PCBs is an important subject not only from the treatment of E-waste but also from the recovery of valuable materials. This article reviews the latest papers on copper recycle processes from waste PCBs developed from laboratories to pilot engineering applications in the latest 5 years. The recovery processes developed from hydrometallurgy, biometallurgy, supercritical fluid, and mechanical-physical are presented. To achieve the higher quality copper from waste PCBs, deep mechanical-physical pretreatment combined with favorable next refine technology should be utilized in a row. All the technologies are tardily developing based on the previous achievement. It is helpful to technology progress of the recourses recovering from PCBs.
\end{abstract}

KEYWORD: waste PCBs; pretreatment; copper recovery; treatment processes

\section{INTRODUCTION}

Currently, end-of-life electrical and electronic equipment (e-waste) is one of the fastest growing wastes all over the world because of the rapid increase in the usage of new equipments with latest technology [1]. Printed circuit boards (PCBs) as the essential part of almost all e-waste are widely used. So waste PCBs is one of the fastest growing waste streams in the world and the average rate of PCBs increased by $14.4 \%$ in China [2].

Waste PCBs are a mixture of glass fiber, polymer materials and multiple kinds of metals, it will create serious pollution with traditional methods of solid waste disposal [3][4]. Many research works have revealed that the composition of metals is between $20 \mathrm{wt} \%-40 \mathrm{wt} \%$. Meanwhile, the concentrations of precious metals such as gold and palladium in waste PCBs are richer than in natural ores. Especially the concentration of copper in waste PCBs is the highest among all metals and 10 times more than that of rich-content mineral. It is necessary for us to develop the waste PCBs recycling industry not only because waste PCBs negatively impacts people's lives but also because it is a potential industry with good prospect [2][5][6]. Although a few reviews have been provide for resource recycling progress of waste PCBs by researchers [5][7][8], some of these reviews involve many aspects, and the summary and discussion of recycling technology is necessary to add some new literatures.

It's very important to develop a kind of process to recycle resources from waste PCBs. It is very difficult and expensive not only to concentrate on minor metals and recover them individually but also to dispose the diverse hazardous substances caused by the processes when all these substances mix up [9]. Under considering cost and environmental benefit, copper is the highest priority to recycle among all metals. This article will review the latest literatures on recycling process of copper from waste PCBs, and present available technology in industry and lab.

\section{PRETREATMENT}

For all recycling methods of PCBs, simply dismantling the electronic components is of necessity prior to recycle precious metals from waste PCBs. However, the contents of different metals and various toxic substances are very disparate in PCBs.

In the process proposed by Chen, hot air is used to melt solders, and pulse jet, using hot air, is used to separate the components and base boards. It is considered as suitable and potential to industrial application. As a result, the disassemble rates of small surface mount components, other surface mount components and pin through hole components 
reach 39.73, 100, and 98.39\%, respectively. However, there is hardly any adverse impact on worker health and the environment due to the sealed dismantling system if the exhaust could be treated properly [9][10].

Mechanical process was employed to separate metals and nonmetals from waste PCBs, and it cannot efficiently recover precious metals, and the metal concentrate obtained from the mechanical process need further purification. Therefore, the mechanical process is usually used as physical pretreatment [11]. The mechanical pre-treatment starts with cutting of the PCBs to reduce their size. This is followed by a grinding process to liberate the component materials. This is an important process, since it affects the efficiency of the subsequent mechanical separation processes and the extraction of valuable metals [12].

Then other pretreatment methods including physical pretreatments and chemical pretreatments are used according to the differences of copper recover ways. Physical pretreatment is to mechanically break and crush PCB scrap, and then according to the differences of physical characteristics of metals and nonmetals, to use one of the methods, including pneumatic separation, magnetic separation, screening, eddy current separation, and electrostatic separation, to obtain the enrichment of metals and nonmetals. Chemical pretreatment is to dissolve base metals such as copper, lead and tin in solution, leaving precious metals in residue, and then to isolate and purify precious metals from the residue. The commonly used chemical pretreatment is nitric acid pretreatment or sulfuric acid and hydrogen peroxide pretreatment [5].

\section{RECYCLING PROCESSES}

Chemical and mechanical methods are two traditional recycling processes for waste PCBs. Chemical methods mainly contain pyrolysis, combustion, hydration, and electrolysis [3]. At present, some processes like open incineration and open acid washing are prohibited strictly in China. Currently, many methods based on hydrometallurgy, pyrometallurgy, biometallurgy, supercritical fluid, and mechanical-physical processes have been developed to identify cost-effective and environmentally sustainable ways of recycling waste PCBs [9]. Although the achievements are remarkable, most of them are still on lab-scale.

\subsection{Hydrometallurgy}

Leaching is the first step in the extraction of metals using hydrometallurgical process. Cyanide leaching has been the predominant method for more than one century due to the selectivity and stability of dicyanoaurate complex in spite of the use of toxic reagents. Several substitutes have recently been proposed as the non-cyanide lixiviants the leaching results of which are effective for recovery of copper [5].

The leaching experiments of $\mathrm{Cu}$ and $\mathrm{Au}$ were carried out with the scrap mobile phone PCBs by electro-generated chlorine as an oxidant, and by employing separate leaching reactor connected with the anode compartment of a $\mathrm{Cl}_{2}$ gas generator. The process has the advantage of leaching precious as well as base metals from waste PCBs because of acquiring high oxidation potential. Also, it is considered environment friendly because the electrogenerated $\mathrm{Cl}_{2}$ leaching can operate in the closed system and chlorine can be reduced during leaching. The results showed that copper leaching increased with increase in concentration of acid, increasing current density, increasing agitation speed and decrease in temperature. In a two-stage leaching process, copper was mostly dissolved (97\%) in 165 min at $25{ }^{\circ} \mathrm{C}$ during the 1 st stage leaching in 2.0 $\mathrm{mol} / \mathrm{L} \mathrm{HCl}$ by electro-generated chlorine at a current density of $714 \mathrm{~A} / \mathrm{m}^{2}$ [13][14].

Huang investigated the leaching characters of PCBs in the agent of $\mathrm{HNO}_{3}-\mathrm{H}_{2} \mathrm{O}_{2}$ - $\mathrm{HF}$ [5]. The results showed that decreasing the particle size increased the copper leaching efficiency. Copper leaching rate was higher than $99 \%$, almost $100 \%$, when $1 \mathrm{~g}$ WPCBs powder was leached under the optimum conditions: particle size of $0.1-0.25 \mathrm{~mm}$, $25 \mathrm{~mL} 80 \%$ (v/v) ionic liquid, $10 \mathrm{~mL} 30 \%$ hydrogen peroxide, solid/liquid ratio of $1 / 25,70{ }^{\circ} \mathrm{C}$ and $2 \mathrm{~h}$. And copper leaching can be modeled with the shrinking core model.

The process of chemical leaching combined with electrochemical process was used for the simultaneous recovery of copper and separation of a gold rich residue from waste PCBs [15]. The PCBs was firstly dissolved in a leaching reactor with a perforated rotating drum, and then the base metals entered a divided electrochemical reactor for the regeneration of the leaching solution with the parallel electro winning of copper. The process performances were evaluated on the basis of the dissolution efficiency, current efficiency and specific energy consumptions. Finally the optimal values of the operating parameters were obtained at the current density of $4 \mathrm{~mA} / \mathrm{cm}^{2}$ and $0.37 \mathrm{M}$ initial $\mathrm{FeCl}_{3}$ concentration. The laboratory scale leaching plant allowed the recovery of a high purity copper deposit of $99.04 \mathrm{wt} \%$ at a current efficiency of $63.84 \%$ and specific energy consumption of $1.75 \mathrm{~kW} \mathrm{~h} / \mathrm{kg}$ cooper. The gold concentration in the remained solid residue was 25 times higher than the gold concentration in the initial WPCB samples.

In summary, leaching technologies mentioned above are technically feasible. However, in order to 
develop an environment-friendly technique for recovery of precious metals from waste PCBs, we should pay more attention to evaluating the cost and environmental impact of techniques.

\subsection{Biohydrometallurgy}

Biohydrometallurgy appears to be an attractive treatment technique owing to its eco-friendly, competent and cost-effective nature. Recently, using microorganism to bioleach metals from waste PCBs was considered as a promising alternative process [16][17]. Many studies were conducted with mesophilic chemolithotrophic or cyanogenic bacteria. The rates of bioleaching of metals from ores were higher by moderate thermophiles than mesophiles and extreme thermophiles [17].

Detailed researches with moderate thermophiles on metals leaching were investigated by Ilyas et al. [17][ 18]. The results revealed that the mixed culture of acidophilic chemolithotrophic bacteria and acidophilic heterotrophic bacteria exhibited greater bioleaching potential than individual cultures. And mixed adapted consortium of acidophilic chemolothotrophic and acidophilic heterotrophic bacteria improved markedly from $12 \mathrm{~g} / \mathrm{L}$ to $20 \mathrm{~g} / \mathrm{L}$ after nearly two year adaptation in mixture of ions. During whole leaching process included acid preleaching operation of 27 days and bioleaching operation of 280 days approximate $86 \% \mathrm{Cu}$ was leached out.

Shah et al. [19] used multi-metal resistant cultures with different medium to evaluate the extraction of $\mathrm{Cu}-\mathrm{Zn}-\mathrm{Ni}$ from waste PCBs. The experiments was carried out with direct bioleaching (one-step) and indirect bioleaching (two-step) processes, the difference of which one-step was PCBs and inoculum were added simultaneously in the medium and two-step was added after the complete oxidation of $\mathrm{Fe}^{2+}$ to $\mathrm{Fe}^{3+}$ iron containing medium. For one-step, $87.50 \% \mathrm{Cu}$ was extracted from $10 \mathrm{~g} \mathrm{~L}^{-1}$ of PCBs within 10-15 days of reaction time, and $99.99 \% \mathrm{Cu}$ was extracted only in 6-8 days for two-step. The result shows the biohydrometallurgy is an eco-friendly process for the recovery of multi-metals from E-waste even at $100 \mathrm{~g}$ $\mathrm{L}^{-1} \mathrm{PCB}$ s concentration.

\subsection{Supercritical water oxidation process}

At supercritical conditions ( $\mathrm{T}>647.3 \mathrm{~K}, \mathrm{P}>22.1$ $\mathrm{MPa}$ ), water has a high solubility for both organics and oxygen, and organic compounds, oxygen, and water form a single and homogeneous phase, which allows oxidation to proceed rapidly by an elimination of the potential interface mass transport limitations. In recent years, this technique has been successfully used for the degradation of waste polymer materials. Polymers could be degraded and recovered as monomers or low molecular weight organic compounds in a very short residence time in supercritical water without causing air pollution and metals become solid deposited at the bottom [16]. It was showed that supercritical water oxidation process was strong enough to decompose the organic compounds of PCBs, and the metals of copper and lead were oxidized into $\mathrm{CuO}, \mathrm{Cu}_{2} \mathrm{O}$ and $\mathrm{PbO}_{2}$ in the process [19][20].

However, supercritical water oxidation process could not recycle pure metals directly. Other treatment must be combined together. Currently, electrokinetic processes combined with water oxidation process have been investigated and applied in ions recycling from PCBs [19]. In the process, the recovery percentages of copper with the supercritical water oxidation process and electrokinetic processes treatment conditions were around $84.2 \%$ under optimum of supercritical water oxidation treatment conditions were $60 \mathrm{~min}, 713 \mathrm{~K}, 30 \mathrm{MPa}$, and electrokinetic treatment time, constant current density were $11 \mathrm{~h}, 20 \mathrm{mAcm}^{-2}$, respectively. In the optimized electrokinetic treatment, $74 \%$ of $\mathrm{Cu}$ was recovered as a deposit on the cathode with a purity of $97.6 \%$. However, the behaviour of all heavy metals except $\mathrm{Cu}$ and $\mathrm{Pb}$ in the PCBs during such combined process was still unmentioned.

\subsection{Mechanical-physical processes}

The mechanical treatment usually was considered as a pretreatment method in metal recycling of PCBs. Many adding process were combined with mechanical treatment, including screening, specific gravity separation, magnetic separation, eddy current separation, and electrostatic separation [3][12]. A mechanical-physical progress contained mechanical two-step crushing, corona electrostatic separating, and recovery was carried out in PCBs recovery by $\mathrm{Li}$ [3]. The results indicated that after two-step crushing the size of particles between 0.6 and $1.2 \mathrm{~mm}$ was suitable for corona electrostatic separating during industrial application. And the nonmetal of waste PCBs attained $80 \%$ weight of a kind of nonmetallic plate that expanded the applying prospect of waste nonmetallic materials.

With the mechanical-physical process, comprehensive materials recovery was obtained reported by Yoo et al. [12]. Waste PCBs were shredded to $<10 \mathrm{~mm}$ using a stamp mill to liberate the various metallic components, and then the scrap were classified into 5 fractions from $<0.6 \mathrm{~mm}$ to $>5$ $\mathrm{mm}$. The fractions of milled printed circuit boards of size $<5.0 \mathrm{~mm}$ were separated into a light fraction of mostly non-metallic components and a heavy fraction of the metallic components by gravity separation using a zig-zag classifier. And the >5.0 $\mathrm{mm}$ fraction and the heavy fraction were subjected to two-step magnetic separation. Through the first 
magnetic separation at 700 Gauss, $92 \%$ of the copper was recovered in the non-magnetic fraction. The cumulative copper concentrate decreased, but the grade increased slightly from $71.6 \%$ to $75.4 \%$ by a second magnetic separation at 3000 Gauss.

Above researchers' results showed that mechanical-physical processes were useful for materials recovery from PCBs, and under the help with different assistant methods. Currently, pure metal or organic could not obtain due to the characters of the recovery apparatus. However, mechanical-physical processes are easily utilized and cost-effective, which lead to it is suited to industrialization.

\section{CONCLUSION}

In summary, copper recovery technologies mentioned above are technically feasible. However, in order to develop an environment-friendly technique for recovery of copper from waste PCBs, we should pay more attention to evaluating the environmental impact of techniques. The results suggest that To achieve the higher quality copper from waste PCBs, deep mechanical-physical pretreatment combined with favorable next refine technology should be utilized in a row.

\section{REFERENCES}

[1] Le, H. L. Jeong, J. Lee, J.-C. Pandey, B. D. Yoo J.-M. \& Huyunh, T. H. 2011. Hydrometallurgical Process for Copper Recovery from Waste Printed Circuit Boards (PCBs). Mineral Processing \& Extractive Metall. Rev. (32): 90-104.

[2] Huang, J. Chen, M. Chen, H. Chen, S. \& Sun, Q. 2014. Leaching behavior of copper from waste printed circuit boards with Brønsted acidic ionic liquid. Waste Management, (34): 483-488.

[3] Li, J. Lu, H. Guo, J. Xu, Z. \& Zhou Y. 2007. Recycle Technology For Recovering Resources And Products From Waste Printed Circuit Boards. Environ. Sci. Technol. 41 (6): 1995-2000.

[4] Menad, N. Bjorkman, B. \& Allain E. G. 1998. Combustion of plastics contained in electric and electronic scrap. Resour., Conserv., Recycl. (24): 65-85.

[5] Zhang, Y. Liu, S. Xie, H. Zeng, X. \& Li, J. 2012. Current status on leaching precious metals from waste printed circuit boards. Procedia Environmental Sciences (16): 560 $-568$

[6] Ehner, T. 1998. Integrated recycling of non-ferrous metal at Boliden Ltd. IEEE International Symposium on Electronics \& the Environment: 42-47.

[7] Shang, H. Wang, P. Luan, X. Wu, L. \& Li, L. 2008. Research progresses of reusing waste printed circuit boards. Environmental Protection of Chemical Industry, (28): 132136.

[8] Li, Y. Sun, W. \& Xing, J. 2008. Study on processing old computer circuit boards and prospects. Environmental Science and Management, (33): 76-79.

[9] Wang, J. \& Xu, Z. 2015. Disposing and Recycling Waste Printed Circuit Boards: Disconnecting, Resource Recovery, and Pollution Control. Environ. Sci. Technol. 49 (2): 721733.

[10] Chen, M. Wang, J. Chen, H. Oladele, A.O. Zhang, M. Zang, H. \& Hu, J. 2013. Electronic Waste Disassembly with Industrial Waste Heat. Environ. Sci. Technol. 47 (21): 12409-12416.

[11] Cui, J. \& Forssberg, E. 2003. Mechanical recycling of waste electric and electronic equipment: a review. $J$. Hazard. Mater. (99): 243-263.

[12] Yoo, J.-M. Jeong, J. Yoo, K. Lee, J. \& Kim, W. 2009. Enrichment of the metallic components from waste printed circuit boards by a mechanical separation process using a stamp mill. Waste Management, (29): 1132-1137.

[13] Kim, E.-y. Kim, M.-s. Lee, J.-c. Jha, M.K. Yoo, K. \& Jeong, J. 2010. Leaching behavior of copper using electrogenerated chlorine in hydroc hloric acid solution, Hydrometallurgy, (100): 95-102.

[14] Kim, E.-y. Kim, M.-s. Lee, J.-c. \& Pandey, B.D. 2011. Selective recovery of gold from waste mobile phone PCBs by hydrometallurgical process. J. Hazard. Mater. (198): 206-215.

[15] Fogarasi, S. Imre-Lucaci, F. Ilea, P. \& Imre-LucaciÁ. 2013. The environmental assessment of two new copper recovery processes from Waste Printed Circuit Boards, $J$. Cleaner Prod. (54): 264-269.

[16] Shah, M.B., Tipre, D. R. \& Dave, S.R. 2014. Chemical and biological processes for multi-metal extraction from waste printed circuit boards of computers and mobile phones, Waste Management \& Research: 1-8.

[17] Ilyas, S. Rua, C. Bhatti, H. N. Ghauri, M. A. \& Anwar M.A. 2010. Column bioleaching of metals from electronic scrap. Hydrometallurgy, (101): 135-140.

[18] Ilyas, S. Anwar, M. A. Niazi, S. B. \& Ghauri, M. A. 2007. Bioleaching of metals from electronic scrap by moderately thermophilic acidophilic bacteria. Hydrometallurgy, (88): $180-188$.

[19] Xiu, F.-R. \& Zhang, F.-S. 2009. Recovery of copper and lead from waste printed circuit boards by supercritical water oxidation combined with electrokinetic process, $J$. Hazard. Mater. 165(1-3): 1002-1007.

[20] Chien, Y.-C. Wang, H. P. Lin, K.-S. \& Yang, Y. W. 2000. Oxidation of printed circuit board wastes in supercritical water, Wat. Res. 34 (17): 4279-4283. 